\title{
SCIDiC
}

\author{
International Journal of Dentistry and Oral Science (IJDOS) \\ ISSN: $2377-8075$
}

\section{Knowledge and Attitude About Rehabilitation Among Partially Edentulous Patients In Madurai City}

Research Article

Selvamani Baskaran ${ }^{1 *}, \mathrm{Umesh}^{2}, \mathrm{Shamly}^{3}$, Ummu kulsum ${ }^{4} \mathrm{Kanimozhi}^{5}, \mathrm{Nini}^{6}$

${ }^{1}$ Post graduate, Department of Public Health dentistry, Best Dental Science College and Hospital, Madurai- 625104, India.

${ }^{2}$ Head of the Department, Department of Public health dentistry, Best Dental Science College and Hospital, Madurai- 625104, India.

${ }^{3}$ Bachelor of dental surgery, Best Dental Science College and Hospital, Madurai- 625104, India.

${ }^{4}$ Bachelor of dental surgery, Best Dental Science College and Hospital, Madurai- 625104, India.

${ }^{5}$ Bachelor of dental surgery, Best Dental Science College and Hospital, Madurai- 625104, India.

${ }^{6}$ Bachelor of dental surgery, Best Dental Science College and Hospital, Madurai- 625104, India.

\section{Abstract}

Objective: The aim of the study is to assess the knowledge and attitude among the partially edentulous patients in Madurai city regarding rehabilitation.

Methods: A 12 item, closed ended, self-administered questionnaire which were framed to assess the knowledge and attitude towards the rehabilitation was used to collect data from the study subjects. After obtaining the informed consent the study participants were asked to fill the questionnaire.

Results: Overall $62.9 \%$ of study population have a sound knowledge about edentulism and rehabilitation and $46.6 \%$ of study population showed positive attitude towards the rehabilitation.

Conclusion: Knowledge and attitude towards rehabilitation still needs to be improved.

Keywords: Attitude; Edentulism; Knowledge; Rehabilitation.

\section{Introduction}

A smile is an inexpensive way to improve your looks. We live in a social world and how we look influences our interactions with others. The face and smile play a crucial role in the creation and maintenance of positive attitudes about one's self and have a tremendous emotional significance [1].

Edentulism is defined as the loss of permanent teeth and is the treatment outcome of a multifactorial process involving biologic process (dental caries, periodontal disease, trauma and others) as we all as nonbiologic factors related to dental procedures ( access to care, patient preferences) [2]. Tooth loss is identified by an edentulous space, which is a gap in the dental arch normally occupied by one tooth or more. It could be partial or complete. A person may lack a few teeth (partially edentulous) or all the teeth in one or both upper and lower jaws (completely edentulous) for various reasons [3]. Bruce observed that the major reason for tooth loss across all the ages were due to dental caries (83\%) followed by periodontal disease (17\%) [4].

Edentulism can lead directly to impairment, functional limitation, physical, psychological, and social disability, and handicap [5]. According to a systematic review evaluating the relationship between oral function and dentition, tooth numbers below a minimum of 20 teeth, with nine to 10 pairs of contacting units, are associated with impaired masticatory efficiency, performance, and masticatory ability (an individual's perception of his/her ability to chew) [6]. This disability could substantially influence the desire to bite, to chew, and to swallow and could lead to a modification of food

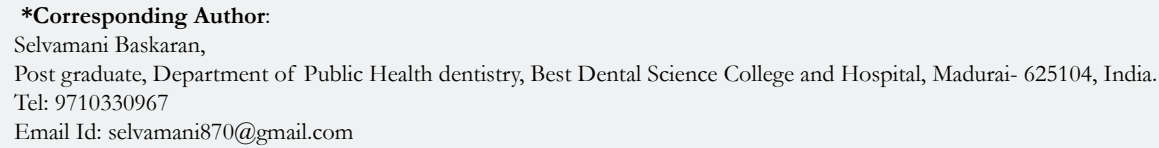

Citation: Selvamani Baskaran, Umesh, Shamly, Ummu kulsum, Kanimozhi, Nini. Knowledge and Attitude About Rehabilitation Among Partially Edentulous Patients In Madurai City. Int J Dentistry Oral Sci. 2021;08(04):2236-2239. doi: http://dx.doi.org/10.19070/2377-8075-21000442

Copyright: Selvamani Baskaran ${ }^{\circ} 2021$. This is an open-access article distributed under the terms of the Creative Commons Attribution License, which permits unrestricted use, distribution and reproduction in any medium, provided the original author and source are credited. 
choices. Bone loss is an on going process following tooth loss, affecting the mandible four times more than the maxilla. The loss of alveolar bone height and width also leads to substantial changes in the soft-tissue profile, such as protrusion of the mandibular lip and chin. Edentulism may also induce an oral dyskinesia, defined as abnormal, involuntary, patterned or stereotyped, and purposeless orofacial movements [5]. Thus, tooth replacement is the only solution for the all such difficulties.

Teeth play an significant role in the general wellness of an indi-

Table 1. Knowledge and attitude towards rehabilitation of teeth among partially edentulous participants.

\begin{tabular}{|c|c|c|c|}
\hline S.No. & Questions & Options & $\begin{array}{l}\text { Respondents } \\
\text { Total }(\%)\end{array}$ \\
\hline \multirow{3}{*}{1} & \multirow{3}{*}{$\begin{array}{l}\text { What is the relation between dental structure and } \\
\text { facial beauty? }\end{array}$} & $\begin{array}{l}\text { a) Independant on one } \\
\text { another }\end{array}$ & $13(8.6)$ \\
\hline & & $\begin{array}{l}\text { b) dependant on one } \\
\text { another }\end{array}$ & $78(52)$ \\
\hline & & c) don't know & $59(39.3)$ \\
\hline \multirow{2}{*}{2} & \multirow{2}{*}{ Do you aware of your no. of missing teeth? } & a)Yes & $118(78.6)$ \\
\hline & & b) No & $32(21.3)$ \\
\hline \multirow{5}{*}{3} & \multirow{5}{*}{$\begin{array}{l}\text { How many teeth is missing? (for } \\
\text { those who said Yes in the previous question) }\end{array}$} & a) 1 & $14(11.8)$ \\
\hline & & b) 2 & $47(39.8)$ \\
\hline & & c) 3 & $23(19.4)$ \\
\hline & & d) 4 & $21(17.7)$ \\
\hline & & e) more than 4 & $13(11)$ \\
\hline \multirow{4}{*}{4} & \multirow{4}{*}{ How did you lose your teeth/tooth? } & a) fallen by itself & $62(41.3)$ \\
\hline & & b) extracted & $60(40)$ \\
\hline & & $\begin{array}{l}\text { c) combination of } \\
\text { both }\end{array}$ & $26(17.3)$ \\
\hline & & d) trauma & $2(1.3)$ \\
\hline \multirow{4}{*}{5} & \multirow{4}{*}{$\begin{array}{l}\text { What is the major problem faced after teeth / tooth } \\
\text { loss? }\end{array}$} & a) Difficulty in eating & $62(41.3)$ \\
\hline & & $\begin{array}{l}\text { b) Change in facial } \\
\text { structure }\end{array}$ & $15(10)$ \\
\hline & & c) slurred speech & $9(6)$ \\
\hline & & d) No problem faced & $64(42.6)$ \\
\hline \multirow{4}{*}{6} & \multirow{4}{*}{$\begin{array}{l}\text { What is the duration without teeth } \\
\qquad / \text { tooth? }\end{array}$} & a) within 1 month & $16(10.6)$ \\
\hline & & b) 1 month - 6month & 19(12.6) \\
\hline & & c) 6 month -1 year & $16(10.6)$ \\
\hline & & d) more than a year & $99(66)$ \\
\hline \multirow{3}{*}{7} & \multirow{3}{*}{ How do you clean your teeth regularly? } & a) using fingers & $42(28)$ \\
\hline & & b) using brush & $92(61.3)$ \\
\hline & & c) others & $16(10.6)$ \\
\hline \multirow{3}{*}{8} & \multirow{3}{*}{ What is the major complication after tooth loss? } & a) bone loss & $35(23.3)$ \\
\hline & & b) tooth drift & $10(6.6)$ \\
\hline & & c) don't know & $105(70)$ \\
\hline \multirow{2}{*}{9} & \multirow{2}{*}{$\begin{array}{l}\text { Do you know that missing teeth/ tooth can be artifi- } \\
\text { cially replaced? }\end{array}$} & a) yes & $137(91.3)$ \\
\hline & & b) no & $13(8.7)$ \\
\hline \multirow{2}{*}{10} & \multirow{2}{*}{ Are you willing to get tooth/teeth replaced artificially? } & a) yes & $54(36)$ \\
\hline & & b) no & $96(64)$ \\
\hline \multirow{4}{*}{11} & \multirow{4}{*}{$\begin{array}{l}\text { What is the reason for not willingness for replacement } \\
\text { ? (For those who said 'No' for the previous question) }\end{array}$} & $\begin{array}{l}\text { a) Financial } \\
\text { constraints }\end{array}$ & $25(26)$ \\
\hline & & b) fear of Dentists & $10(10.4)$ \\
\hline & & $\begin{array}{l}\text { c) Not necessary to } \\
\text { replace }\end{array}$ & $47(48.9)$ \\
\hline & & d) others & $14(14.5)$ \\
\hline \multirow{3}{*}{12} & \multirow{3}{*}{$\begin{array}{l}\text { What type of tooth/teeth you want to get replaced } \\
\text { with? (for those who said 'yes' for the question } 10 .\end{array}$} & a) removable partial & $18(33.3)$ \\
\hline & & b) fixed partial & $33(61.1)$ \\
\hline & & c) implant & $3(5.5)$ \\
\hline
\end{tabular}


vidual and also in the maintanence of affirmative self image. Loss of teeth not only adversely affects the body physiology but also disturbs the psychology of the individual. It considerably reduces the quality of life. It is a very upsetting experience and a psychologically serious event in a life of an individual which requires immediate rehabilitation [7].

India holds a population of more than 1 billion people, in which 77 million people are either partially or fully edentulous [8]. The number of patients that should be visiting a dentist for dental prosthetic rehabilitation treatment should be high, but, due to various reasons, such as lack of awareness, poor socioeconomic status, lack of a specialized dentalclinics, etc. this number is still unknown. Various factors are responsible for patient acceptance and adaptation to a new dental prosthesis which can be anatomical, physiological, psychological and or prosthodontic factors. Above all it depends on the attitude of the patients towards prosthetic treatment [9]. Hence, the aim of the study is to assess the knowledge, attitude regarding the dental rehabilitation among the partially edentulous patients in Maduraicity.

\section{Materials and Methods}

It is a cross sectional study done on the 150 people in Madurai city selected through purposive sampling. Ethical clearance was obtained from the Institutional ethical review board of Best dental science college and permission to conduct the study was obtained. The aim and objectives of the research and the content of the questionnaire was explained to the participants. Written informed consent of participation was obtained from them before the start of the study. Participation in this study was purely on voluntary basis. It was emphasized that strict confidentiality would be maintained at all times \& that no names or personal details will be used in the write up of the study. Those who are intellectually challenged, persons below 20 years of age and above age of 60 , completely edentulous patients, patients wearing dentures or any fixed prosthesis or implants and persons with dentulous teeth were excluded. The research was conducted between $\mathrm{Au}$ gust to September of 2019. The pilot study was conducted for a period of two week in the month of July 2019. The feasibility of study and Validity of the questionnaire was analysed. After ana- lysing the results of the Pilot study results necessary changes in the questionnaire were made and the main survey was conducted. The content validity of the questionnaire was checked by a panel of experts from the Department of Public Health Dentistry, Best dental science college, Madurai. 12 Questions were formulated in a way that would help in extracting the required information from the participants. The face validity of the questionnaire was assessed by the experts. Ambiguous questions were reframed and the final version was designed. A 12 item, close ended, self-administered questionnaire was used to collect data from the study subjects. The questionnaire consisted of 12 close ended multiple choice questions which were framed to assess the knowledge and attitude towards rehabilitation and was translated to local language (Tamil).

All the participants were given 10 minutes to fill the questionnaire. All subjects were provided written informed consent to participate in the study. The participation was voluntary, and confidentiality was assured.

\section{Results}

The present study was an attempt to evaluate the knowledge, attitude regarding rehabilitation among partially edentulous patients in Madurai city. The results are based upon the data obtained from 150 participants. The data obtained in the present survey were entered in to excel spreadsheets. A master table was prepared. Descriptive statistics were used to find out the frequency of study people answering the different options. Overall $62.9 \%$ of study population have a knowledge about edentulism and rehabilitation and $46.6 \%$ of study population showed positive attitude towards the rehabilitation.

\section{Discussion}

The study questionnaire was anonymous to prevent social desirability bias. The questionnaire was filled in the presence of investigator in prescribed time to minimize bias. The above results suggests that though $52 \%$ have said that dental structure and $\mathrm{fa}$ cial beauty are dependant on each other and $91.3 \%$ knowing the availability of rehabilitation of teeth, majority of the participants

Figure 1.

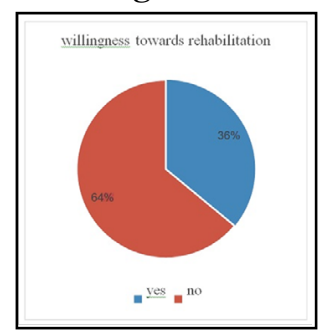

Figure 2 .

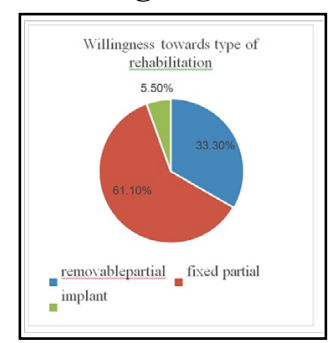


Figure 3.

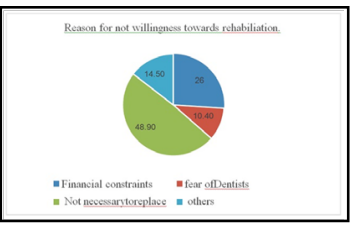

$(64 \%)$ didn't want to replace their teeth. Most of the participants said that it is not necessary to replace their teeth $(48.9 \%)$ as their reason for their edentulousness compared to financial constraints which was chosen by $26 \%$ suggesting that lack of awareness and poor attitude towards rehabilitation taking the upperhand over the financial constraints which is in contrast to the findings of Shigli K et al [1]. Nearly $21 \%$ of them were not aware of their no. missing teeth which shows their concern towards their oral care. $70 \%$ of them were not aware of the complication that arise after tooth loss showing poor knowledge and $66 \%$ of them had been more than a year with missing teeth showing negative attitude towards rehabilitation.

In the present study $41.3 \%$ have said difficulty in eating, This can be explained by the fact that most people in India are more concerned about the masticatory function of a prosthesis rather than esthetics, a finding also observed by Shigli K et al in 2007 [1]. Most of the people have said periodontal problems as the reason for the tooth loss which is in accordance with the finding of $\mathrm{Nu}-$ vuula $\mathrm{S}$ et al [10]. This could be due to the lack of awareness and negligent oral hygiene maintenance, hence periodontal problems.

In the current study $33.3 \%$ showed positive attitude towards removable prosthesis, $61.1 \%$ showed positive towards fixed prosthesis. Attitude towards implant mode of replacement is $5.5 \%$. The results are almost similar to the findings of the study done by Shreya Gupta et al [9] in Jabalpur city and Siva Teja et al [8]. In contrast to the present study, the study findings of Kamal Shigli et al shows that only $6.9 \%$ have low felt needs. In this study $64 \%$ were not willing for rehabilitation which is similar to a study conducted by Kuzhalvaimozhi etal [11].

Gerritsen et al in 2010 did a systematic review and meta-analysis on tooth loss and Oral Health Related Quality of Life (OHRQoL), and found a fairly strong evidence that tooth loss is associated with impairment of OHRQoL [12]. Rehabilitation is an important aspect of treatment which increases the oral health related quality of life. It is the very duty of the dentist to provide adequate information to the community and change their perception towards rehabilitation. From the results it can be noted that the knowledge towards existence of the artificial replacement of the teeth is higher but the willingness towards the same is limited suggesting the existence of barriers in the community. The limitation of the study is that analysis was not done with the socioeconomic status of the participants. Future studies should determine how the dental profession and society might address an increased demand for services among people who have limited financial resources. Also, studies can be conducted that take in to consideration various cultural aspects of a wider population to learn their influence on attitudes towards replacement of missingteeth.

\section{Conclusion}

Rehabilitation and disability limitation though considered as intervention for tertiary level of prevention, provides better and significant quality of life to the people if turned up earlier. The finding of our study suggests that knowledge and attitude towards rehabilitation remains poor. Hence edentulous patients need to be health educated regarding the complications of tooth loss and various treatment options availability for the replacement and to increase their willingness towards it. The present study reflects the knowledge and attitude regarding rehabilitation of teeth among partially edentulous persons in Madurai city.

\section{References}

[1]. Shigli K, Hebbal M, Angadi GS. Attitudes towards replacement of teeth among patients at the Institute of Dental Sciences, Belgaum, India. J Dent Educ. 2007 Nov;71(11):1467-75. Pubmed PMID: 17971577.

[2]. Sonkesariya S, Jain D, Shakya P, Agrawal R, Prasad SV. Prevalence of Dentulism, Partial Edentulism and Complete Edentulism in Rural and Urban Population of Malwa Region of India: A Population-based Study. Int J Prosthodont Restor Dent. 2014;4(4):112-9.

[3]. Madhankumar S, Mohamed K, Natarajan S, Kumar VA, Athiban I, Padmanabhan TV. Prevalence of partial edentulousness among the patients reporting to the Department of Prosthodontics Sri Ramachandra University Chennai, India: An epidemiological study. Journal of pharmacy \& bioallied sciences. 2015 Aug;7(Suppl2):S643.

[4]. Bruce I, Nyako EA, Adobo J. Dental service utilisation at the Korle Bu teaching hospital. African Journal of Oral Health Sciences. 2001;2(3):64-7.

[5]. Emami E, de Souza RF, Kabawat M, Feine JS. The impact of edentulism on oral and general health. International journal of dentistry. 2013 May 8;2013.

[6]. Gotfredsen K, Walls AW. What dentition assures oral function? Clin Oral Implants Res. 2007 Jun;18 Suppl 3:34-45. Erratum in: Clin Oral Implants Res. 2008 Mar;19(3):326-8. Pubmed PMID: 17594368.

[7]. Shekhawat KS, Prasanya R, Senthil M, Chauhan A. Replacement of missing teeth among patients-factors determining the attitude. Journal of Scientific Dentistry. 2016;6(2):23-9.

[8]. Teja SS, Kumar VR, George VT. A survey to evaluate the awareness of various treatment modalities to replace missing teeth among patients visiting Kasturba Hospital, Manipal: A prosthodontic perspective. World Journal of Dentistry. 2015 Oct 1;6(4):217-21.

[9]. Gupta S, Mantri SS, Bhasin A. Knowledge and attitude towards prosthodontic rehabilitation and utilization of dental services by central India population of Jabalpur city, India. Annals of Medical and Health Sciences Research.2018.

[10]. Nuvvula S, Chava VK, Nuvvula S. Primary culprit for tooth loss!! J Indian Soc Periodontol. 2016 Mar-Apr;20(2):222-4. Pubmed PMID: 27143841

[11]. Kuzhalvaimozhi P, Duraisamy R, Ganapathy D. Awareness and knowledge of various treatment options for replacement of missing teeth in patients at Saveetha Dental College and Hospitals-A questionnaire-based study. Drug Invention Today. 2020 Apr; 1:13(4).

[12]. Gerritsen AE, Allen PF, Witter DJ, Bronkhorst EM, Creugers NH. Tooth loss and oral health-related quality of life: a systematic review and metaanalysis. Health Qual Life Outcomes. 2010 Nov 5;8:126. Pubmed PMID: 21050499. 